\title{
Analysis on Factor Decomposition Effect of Export on Economic Growth in China: Global Value Chain Perspective
}

\author{
Zheng Guojiao \\ School of Economic and Management, Shanghai Polytechnic University, 2360Jinhai Road, Pudong New \\ District, Shanghai, China \\ gjzheng@sspu.edu.cn
}

Keywords: Domestic trade in value added, Export Contribution to GDP, Global value chain, Factor decomposition analysis

\begin{abstract}
In the context of new international division of labor (NIDL) and deepening trend of the Global Value Chain (GVC), the traditional trade statistics faces "double accounting” issue. A new methodology that measures trade in domestic value-added can solve this problem. In this paper, we use the new method to calculate Export Contribution to GDP (ECG) in China by the WIOD database. The paper also analyzes the factors effect ECG in China by industrial structure decomposition analysis. The results show that in 1995-2009, the demand scale effect was the most crucial positive factor for the ECG, while the Vax (Value-added export ratio) effect is negative, which shows the increasing intensity of their participation in the global value chain. China have increased the ECG by turning labor-intensive products to technology-intensive and capital-intensive products. China should continue to improve the export structure and develop services to enhance the pulling effect of export on economic growth.
\end{abstract}

\section{Introduction}

China is the largest developing countries and the typical representatives of emerging economy. In 2015, China's GDP reached \$11 trillion and its export reached \$2.3 trillion, makes it the world's second largest economy respectively. With huge population and large-sized production, trade plays a significant role in China's economic development. With the further of reform and opening, China is much more depending on export than before according to the traditional trade statistics. Thus, it is important and interesting to analysis the export contribution to GDP and analyze the factor behind the differences. However, in recent years, due to the rapid integration in international production networks and evolution of global value chain (GVC), the trade in parts and components increasingly dominates international trade. It then has been argued explicitly that standard trade statistics on final products do not give accurate information anymore about the actual value, which a country adds in the global production process. Especially for countries which has to import a large amount of intermediate inputs to assemble its exports, such as China. In this paper, we aim to estimate the export contribution to GDP from the domestic value-added perspective, which contributes directly to their total gross domestic product. Then we decompose its influential factors by structure decomposition analysis, at last we give some policy recommendations.

The paper is organized as follow: Section II reviews the recent relevant literatures in this field; Section III describes the methodology and data we use in this paper to measure the ECG and to analyze the influential factors effect; Section IV shows the results from factor decomposition analysis; Section $\mathrm{V}$ is the conclusion and policy implications.

\section{Literature Review}

Since China joined WTO in 2001, two interrelated important phenomena have attracted a great deal of interests by researchers. The first one is the slicing up the value chain, where the production processes are sliced into many stages in different locations, include different countries. The second one is, based on the gross trade statistics, China's Export Dependence reached to 67\%, high 
dependence on export also pushes up China's trade surplus/GDP ratio from 2.01\% in 2000 to $7.59 \%$ in 2007, which makes China suffer from strong accusation of dumping cheap products and currency manipulating. Many scholars argue that the traditional trade statistics exaggerated the export volume in China and call for modification of the methods and new trade statistical system (Shen Lisheng, 2005; Huang Yan, 2003). Therefore, how to precisely measure ECG is still one important question needs to be answered.

So far, most of the literatures measuring the export scale are focused on one country's nominal export value. It can reflect the degree of export contribution to GDP to some extent, however, some issues, such as the statistics standards, the processing exports etc., haven't been taken into consideration. For this reason, the index cannot reflect the export effect objectively, many scholars put forward the trade in Value-added calculation method, which can state the real benefit from export and reflect the exact pulling effect to GDP growth.

Though the literatures generally suggest that the conventional calculation method overestimated China's trade dependence, most of them still mainly use the total trade database. There is very little literature providing both measurement on GDP and value added in international trade, based on the domestic value added database. In the context of international division of labor and deepening of the global production value chain, the value added trade statistics can settle the "double accounting" issues. The new trade statistics can truly reflect the contribution of a country's domestic production to the final consumption product. In 2013, the Trade in Value Added (TiVA) database has been developed by OECD and WTO. Since then, many more studies have been done based on the TiVA data. This paper is to reanalyze the ECG of China using domestic value added as the indicator of economic benefits, which can give us a better understanding of export structure and the pulling effect factors behind it.

\section{Methodology and Data}

\subsection{ECG calculation}

Here we use a new method to calculate the ECG (Export Contribution to GDP): the calculation by trade in value added.

Value added ECG calculation. As previously mentioned, since 2000s many scholars criticized the Grossman's method for its simplicity and being imprecise. A modified calculation based on value-added trade has been developed based on the work of Johnson and Noguere (2012) and Koopman and Wei (2010). The formula is as follow:

$$
E C G=\frac{v a_{i j}}{G D P}
$$

Where $v a_{i j}$ is the domestic value added in trade, ECG is the export contribution to GDP base on the value added trade.

The key method to calculate domestic value added is Input-Output Analysis(IOA) which was first developed by Leontief in 1950s. Earlier IOA are all based on single region Input-output table. Recently it is more replaced by Multiregional Input-output table when analyzing international trade. The most widely applied approach for calculating domestic value added is proposed by Johnson and Noguera (2012), on assumption that intermediation trade flows between regions are only determined by reproduction and final consumption.

In this paper, we assume there are $\mathrm{S}$ sectors and $\mathrm{N}$ countries. Each country produces a single differentiated tradable good within each sector, and we define the quantity of output produced in sector s of country i to be $y_{i}(s)$. This good is produced by combining local inputs with domestic and imported intermediate goods. It is then either used to satisfy final demand (equivalently, “consumed") or used as an intermediate input in production. The market clearing condition in value terms as: 


$$
y_{i}(s)=\sum_{j} \sum_{t} m_{i j}(s, t)+\sum_{j} c_{i j}(s)
$$

In Eq. (2), $i$ and $j$ denote countries or regions. $s$ and $t$ denote the sectors. $y_{i}(s)$ denotes the output of country $i$ in sector $s . m_{i j}(s, t)$ denotes country $j$ 's consumption of intermediate products from country $i$ in sector $s . c_{i j}(s)$ denotes country $j$ 's consumption of final products from country $i$ in sector s. Eq. (2) shows that output is divided into domestic final use, domestic intermediate use, and gross exports.

Assume there are $\mathrm{N}$ countries and S sectors, the world's total output can be shown in matrix form:

$$
y=A y+\sum_{j} c_{j}
$$

where, $y$ is the output block matrix,

$$
y=\left(\begin{array}{l}
y_{1} \\
y_{2} \\
\vdots \\
y_{n}
\end{array}\right)
$$

$A$ is the world's input-output

$$
A=\left(\begin{array}{ccc}
A_{11} & \ldots & A_{1 n} \\
\vdots & \ddots & \vdots \\
A_{m 1} & \cdots & A_{m n}
\end{array}\right), c_{j} \text { is country } J \text { 's final consumption matrix, } \quad c_{j}=\left(\begin{array}{l}
c_{1 j} \\
c_{2 j} \\
\vdots \\
c_{N j}
\end{array}\right)
$$

Using this framework, the world's output can be rewrite into Leontief inverse matrix as:

$$
y=\sum_{j}(I-A)^{-1} c_{j}
$$

Eq. (4) thus decomposes output from each source country i into the amount of output from the source used to produce final goods absorbed in country $j$. To make this explicit, we define:

$$
\left(\begin{array}{l}
y_{1 j} \\
y_{2 j} \\
\vdots \\
y_{N j}
\end{array}\right)=(I-A)^{-1} c_{j}
$$

To calculate the value added associated with these implicit output transfers, define the ratio of value added to output for each sector within country $i$, as

$$
r_{i}(t)=1-\sum_{j} \sum_{s} A_{j i}(s, t)
$$

Thus, the total value added produced in sector $s$ in source country $i$ and absorbed in destination country $j$ is

$$
v a_{i j}(s)=r_{i}(s) y_{i i}(s)
$$

Total value added produced in $i$ and absorbed in $j$ is then

$$
v a_{i j}=\sum_{s} v a_{i j}(s)
$$

The sector-level bilateral value added to export ratio is given by $v a_{i j}(s) / x_{i j}(s) . x_{i j}(s)$ represents the sector conventional gross export amount. 


\subsection{Structure Decomposition Analysis for ECG}

From above analysis, to sector-level perspective, we can divide ECG into three components as shown in equation 9, industrial value added export ratio (VAX), structural proportion and conventional export dependence(RDT).

$$
\operatorname{ECG}(s)=100 \times \frac{v a_{i j}(s)}{x_{i j}(s)} \times \frac{x_{i j}(s)}{x_{i j}} \times \frac{x_{i j}}{G D P}
$$

Where $x_{i j}(s)$ represents the sector conventional gross export amount. $x_{i j}$ represents the national conventional gross export amount.

Then, we can conclude that:

$$
E C G=\operatorname{Vax}_{i j} \times x r_{i j} \times R D T
$$

Further decompose the ECG, we get:

$$
\begin{aligned}
\Delta E C G= & \underbrace{\Delta \operatorname{Vax} \times x r_{0} \times R D T_{0}}_{a}+\underbrace{\operatorname{Vax} \times \Delta x r \times R D T_{0}}_{b}+\underbrace{\operatorname{Vax} x_{1} \times x r_{1} \times \Delta R D T}_{c} \\
& \text { VAX ratio effect exports structure effect demand expansion effect }
\end{aligned}
$$

\subsection{Data sources}

The data source of structure decomposition analysis (SDA) in this paper is the World Input Output Database (WIOD), which provides time-series of inter-country input-output tables for 40 countries. Due to its clear description of inter-country and inter-sector flows along global production process, the input-output method has been widely accepted to measure domestic-value-added of international trade (Koopman, 2014). To highlight our analysis, we focus the measurement in 15 major economics, combine EU countries as integration and the rest of the world as ROW. Given that the service trade is limited in China, we combine the service industries into 2 catalogs, which are consumer service and producer services. The world input-output table contains 17 industries, 15 economics finally.

\section{Results and Discussions}

\subsection{The trend of ECG in China}

Based on the above mentioned method, we calculated the ECG of China in 1995-2011 from domestic-value-added perspective, the results are as follows:

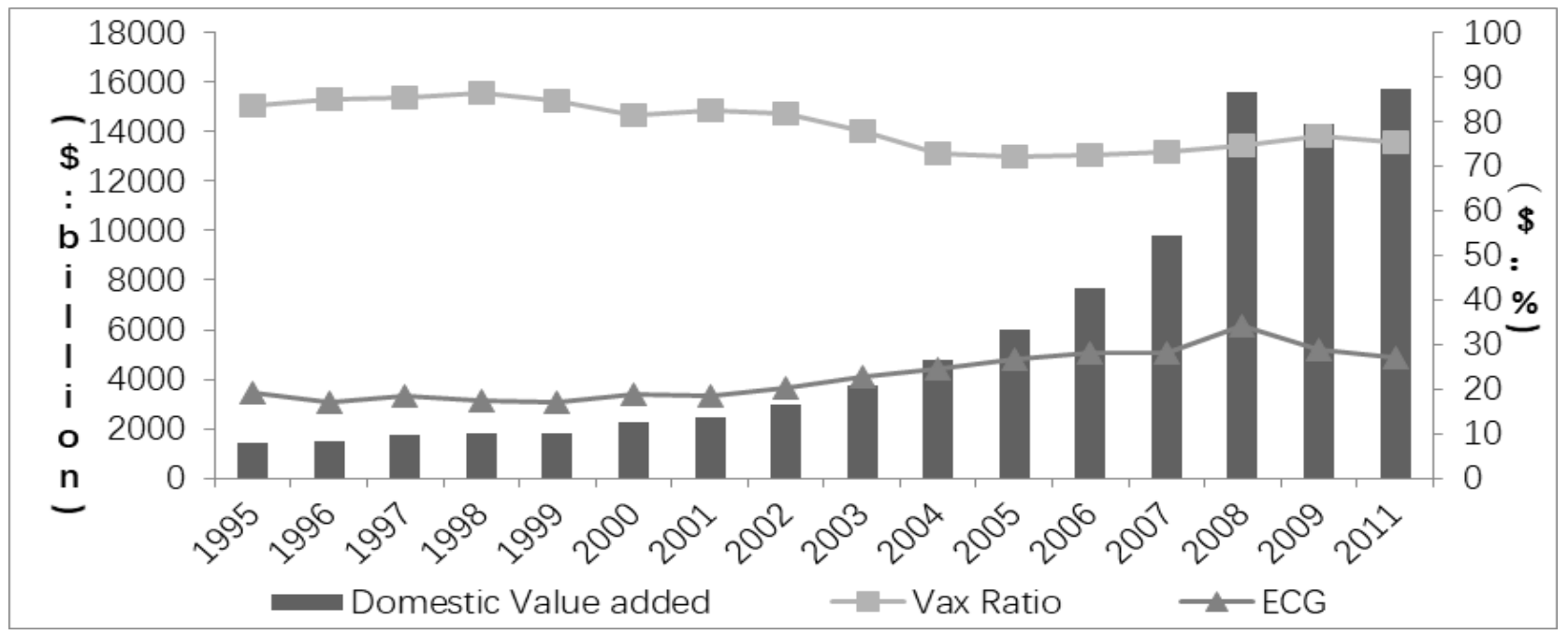

Fig.1 The export contribution to GDP of China in1995-2011. 
As displayed in figure 1, China's ECG generally hold on an upward slope trend. It rose from $19.2 \%$ to $26.7 \%$ during the period of $1995-2011$, the average annual rate of growth is $2.9 \%$. From the value-added trade statistics, China's domestic value added was much higher than before joining the WTO, after joining WTO, the export volumes increased rapidly which results in fast increase in export dependency ratio. The ECG reached the peak point $34.5 \%$ in 2008 , it decreased a bit afterward due to the global financial crisis.

It also shows that China's Vax ratio is decreasing in sample years, it can be explained that China is doing much more processing and assembly manufacture. The overestimation of conventional RDT in China is much higher and much more needed for adjustment. The results also tell us China is involved in the international division of labor more and more deeply.

\subsection{Overall ECG decomposition}

ECG decomposition could offer insight into comprehension of ECG and help us trace it by different industries. VAX ratio can measure a country or region's integration in global value chain (Johnson and Noguera, 2012). Table 1 shows China see a decline on the VAX ratio. In China, it declines from $83.6 \%$ in 1995 to $76.5 \%$ in 2009 . The peak point is $86.4 \%$ in 1998 , the turning point of VAX ratio is 2001 when China joins the WTO. Given that China has become the largest exporter taking active participation in global value chain. It contains much more foreign value, so its VAX ratio decreased gradually since 2005. In China, demand expansion effect is positive and greater than the effect of VAX ratio. The fact that China's demand-expansion-effect (0.1189) in 2009 was significantly higher than 1995 (0.0161) while the VAX-ratio-effect was lower than before indicating that China's export-oriented economic growth was more led by scale-expansion. China should improve the content of export products and weaken the impact of demand expansion effect on ECG gradually.

Table 1.Overall decomposition of ECG of China (1995/2002and1995/2009)

\begin{tabular}{ccccccc}
\hline Time & ECG & $\begin{array}{c}\text { Total } \\
\text { VAX }\end{array}$ & RDT & Decomposition & $\begin{array}{c}\text { VAX ratio } \\
\text { effect }\end{array}$ & $\begin{array}{c}\text { Demand } \\
\text { expansion } \\
\text { effect }\end{array}$ \\
\hline $\mathbf{1 9 9 5}$ & $19.14 \%$ & 0.836 & $23.06 \%$ & $1995 / 2002$ & -0.0046 & 0.0161 \\
$\mathbf{2 0 0 2}$ & $20.28 \%$ & 0.817 & $25.04 \%$ & $2002 / 2009$ & -0.0201 & 0.1044 \\
$\mathbf{2 0 0 9}$ & $28.74 \%$ & 0.765 & $39.34 \%$ & $1995 / 2009$ & -0.0231 & 0.1189 \\
\hline
\end{tabular}

China's ECG ranged from $19.1 \%$ in 1995 to $28.7 \%$ in 2009, what are the factors behind this change? The decomposition analysis shows(Table 2), among the three main factors determines the ECG, the demand expansion effect is the dominators, followed by exports structure effect. The VAX ratio effect is the weakest. Demand expansion effect is almost always positive which states the scales of China's exports expanded considerably. There are industries differences in structure effect. In labor-intensive industries, its effect is negative, while in capital and knowledge-intensive industries, its effect is positive. This phenomenon reflects that the export structure has optimized a lot in China.

China's ECG ranged from $19.1 \%$ in 1995 to $28.7 \%$ in 2009, what are the factors behind this change? The decomposition analysis shows (Table 2), among the three main factors determines the ECG, the demand expansion effect is the dominators, followed by exports structure effect. The VAX ratio effect is the weakest. Demand expansion effect is usually positive which states the scales of China's exports expanded considerably. There are industries differences in structure effect. In labor-intensive industries, its effect is negative, while in capital and knowledge-intensive industries, its effect is positive. This phenomenon reflects that the export structure has optimized a lot in China. Export in technology-intensive products is playing a more important role in increase of China's ECG. As to the details, the structure effect of textiles and textile products is the most negative (2.14\%), the structure effect of machinery is the most positive $(0.57 \%)$. The result shows that in last few decades, a considerable progress has been taken place in China's technology-intensive and capital-intensive industries, which played a leading role in China's international trade. But the 
service exports are still weak; its contribution to economic growth is limited.

Table 2. Structure decomposition analysis (SDA) of ECG of China.

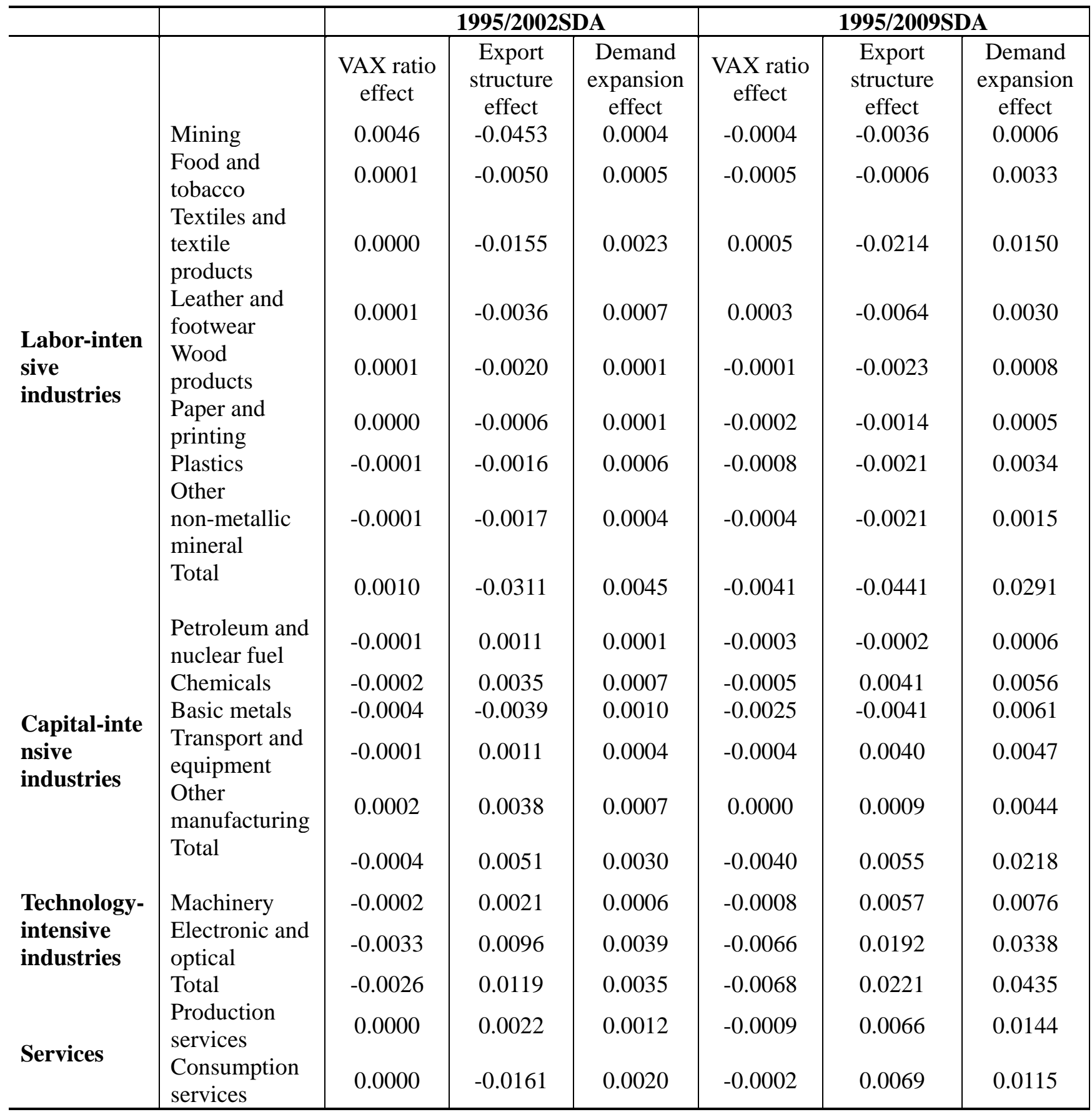

Viewed from the VAX ratio effect, most sectors are negative. As an indicator to measure the participation rate in global value chain, the declinations in VAX ratio tell us: although China has integrated in the world production network, China's share in the global value chain is reducing. Looking into the specific sectors, the result shows consumers' service sectors, mining have a relative higher domestic value added. The producers' service sectors and most manufacturing industries have a lower value added and the VAX ratio are decreasing. Like the electronic industry, its VAX ratio negative effect is the highest (0.66\%), and demand expansion effect is $3.38 \%$.

\section{Conclusion}

Based on a harmonized inter-country input-output database WIOD and the ECG calculation methods, we explore the ECG and their decompositions factors link to value-added trade about 
China in1995-2009. The results show that the increasing role of emerging countries in international fragmentation of production has considerably changed global trade chain and market. China's export volume and its contribution to GDP have significantly been overestimated compared to conventional statistics methods of calculation. The VAX ratio effect is negative, which result from reducing the share in obtained value added in international exports of final products. The promotion of ECG was mainly caused by export demand expansion in sample periods.

In sector level, using the decomposition methods, we found that the consumption expansion effect is the decisive factor, followed by exports structure effect, and the VAX ratio effect is the weakest. Under the value added export accounting, China's mass trade surplus is reduced and rough balance is achieved. It shifts from labor-intensive industries to capital and technology-intensive industries gradually. The competitiveness of China's technology-intensive industries continues to improve, As the "world factory", China should focus on improving her position in international labor division and shift from pursuing quantity expansion to quality improving and move upward on the Global Value Chain. The Chinese government should support development of financial services and other knowledge-intensive services to optimize the export structure and maintain its pulling effects on economic growth.

\section{References}

[1] Grassman, S.. Long-term Trends in Openness of National Economics [J]. Oxford Economic Papers 32, 1980: 181-205.

[2] Johnson, R. C., Noguera, G. Accounting for Intermediates: Production Sharing and Trade in Value Added [J]. Journal of International Economics, 2012, 86(2): 224-236.

[3] Koopman, R. Z, Wei, S. J.. Tracing Value-added and Double Counting in Gross Exports [J]. American Economic Review, 2014, 104(2): 459-494.

[4] Balassa, B, (1978) “Exports and Economic Growth: Further Evidence.” Journal of Development Economics (5), 181-189.

[5] Wu.Y.R \&Zhou Z Y, (2006) “Changing bilateral trade between China and India.” Journal of Asia Economics17 (3), 509-518.

[6] Timmer .M.P etal, (2012) “New Measures of European Competitiveness: A Global Value Chain Perspective, WIOD Working Paper9.

[7] Hummels D etal. The Nature and Growth of Vertical Specialization in World Trade [J]. Journal of International Economics, 2001(54), 75-96.

[8] Koopman R etal. Give Credit Where Credit Is Due: Tracing Value Added in Global Production Chains [J]. NBER Working Paper No.16426.

[9] Lutz E. Trade in non-factor Services: Past Trend and Current Issues [J].Staff Working Paper, 1980. 